\title{
Implementation of SFCL in Three-Phase System for Fault
}

\author{
Sankalpa Bohidar, Renu Sharma
}

\begin{abstract}
The main aim of this paper is to place "Superconducting Fault Current Limiter" (SFCL) in a threephase power scheme for fault evaluation. superconducting fault current limiter (SFCL) in a three-phase system for the purpose of fault analysis. The implementation of the SFCL mitigates a burden on the network along with the reliability improvement of an electrical system. In this paper a typical three phase system is designed using Simulink/Sim Power System and analysis of LG and LL fault is done with and without employing SFCL in the system.
\end{abstract}

Keywords-Current limiter, three-phase, LG fault, LL fault, SFCL.

\section{INTRODUCTION}

The launch of new technology equipment with more demanding electronic components based on power quality and advanced digital measurement requires a strict supply of more consumers. It is a great opportunity to further study the limitations identified in the law and standardization, along with the financial tools needed to pose technical challenges. The objective of the SFCL system is to ensure proper operation and achieve the goals stated by the distributor. Supply quality is expected to be high as it is affected by several incidents [1] that may occur in medium voltage networks and substations. Therefore, for companies that have such a system installed, the costs are greatly reduced. The main important part of this system is a thorough analysis to determine the appropriate location to install SFCL technology before installation. The main purpose of the analysis is to improve supply quality and minimize associated negative incidents at HV / MV substations.

Smart grids are anticipated to be the next level of power grids. Incorporate modern communication techniques and the allocation of clean energy sources into the distribution network. Smart grids provide a distinctive chance to move the electricity or utility industry to a fresh age of efficiency, availability, safety and effectiveness. The integration of flexible sources of energy into the primary grid [2] is a significant characteristic of smart grids. As demand for electricity continues to raise, the incorporation of "Decentralized Energy Resources" (DER) into the primary grid has risen considerably in order to obtain a continuous rise in demand. When DER is integrated extensively into the power grid, the fault current value rises and the relay adjustment is lost [3]. The introduction of DER increases fault current, so low-rated traditional protection devices

Sankalpa Bohidar, Department of Electrical Engineering, Institute of Technical Education and Research, Siksha 'O' Anusandhan(Deemed to be University), Bhubaneswar, Odisha, India.

Renu Sharma, Department of Electrical Engineering, Institute of Technical Education and Research, Siksha 'O' Anusandhan(Deemed to be University), Bhubaneswar, Odisha, India. (Email: renusharma@soa.ac.in)
Revised Manuscript Received on September 14, 2019.

cannot be protected with smart grids as such systems requires significant investment with some modification. Incompetence of protection systems to interrupt "shortcircuit currents" can result to extensive harm and may endanger the accuracy and sustainability of the power grid.

"Superconducting fault current limiter" (SFCL) is a new and advanced Development that is capable of controlling or reducing fault currents in "smart grids" [4]. SFCL improves transient stability of power systems by providing suppression of the first cycle of fault current [5]. Superconducting materials exhibit very non-linear behaviour and are quite helpful for building "fault current limiters". SFCL introduces a Moreover, if the system breaks down and the quantity of the fault current exceeds the threshold value of the superconducting material which act as a limiter, then in this case the unit will shifts from its superconducting, i.e. low strength, to standard, i.e. high impedance state, Minimizes fault current A level that can be easily broken with conventional protective devices [6].

\section{FAULT ANALYSIS OF SFCL IN POWER SYSTEM}

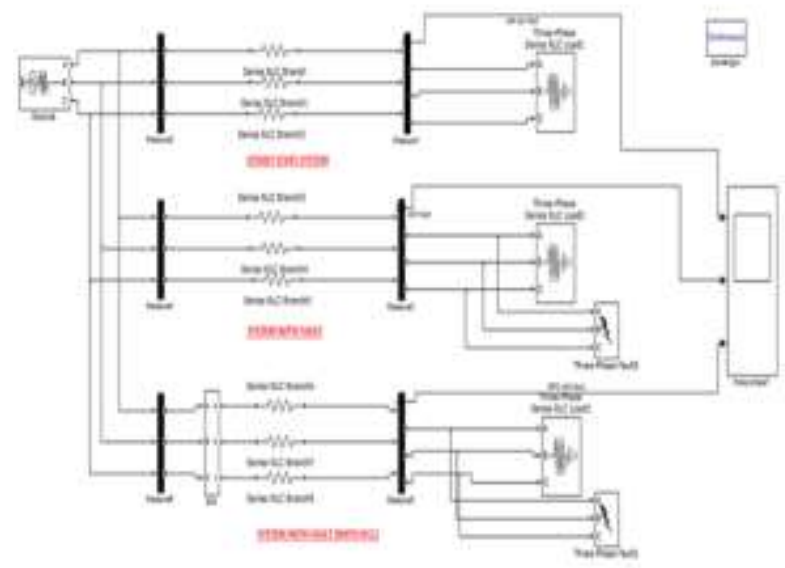

Fig.1(a): Steady state simulation model of three Phase System, at the time of fault without SFCL and with SFCL

A three-phase system is planned using the Simulink / Sim Power System [7], [8] shown in Figure 1 (a). In the above fig.1(a), a source is provided to the system with three phase supply and the SFCL is inserted in between the three-phase source and a load to limit the value of current. Table 1 shows all the electrical parameters along with its values used herein. 
Table:1 Perameter values of tee peoposed power wweil

\begin{tabular}{|c|c|}
\hline Parameters & Value \\
\hline AC Voltane $V_{\text {ft }}$ & 1732 V (RMS) (Per Phase) \\
\hline Source Resistiace & $00 \mathrm{in}$ \\
\hline Transmisuon Line Revistumere & 10 \\
\hline Load Resistance & 500 \\
\hline
\end{tabular}

\section{A. System Without Fault}

Current waveform in the absence of any fault condition within the system is assume to be steady and stable with no system failure. In other words, it can be said that under such condition of no fault the current flowing in the system is very much stable with zero starting time and current value. The peak current value during normal operation is found to be square root of thousand. For the purpose of cooling down the superconducting material, a liquid nitrogen is employed due to which the temperature maintains at constant value of seventy-seven kelvin. In case of the temperature of selected superconducting material is seen to be less than the threshold, then in such circumstances the SFCL continues in superconductor or "zero resistance state". The voltage drops of the "fault current limiter" through ordinary operation is a very small value roughly equivalent to zero to give zero resistance under ordinary working circumstances. Loss during ordinary system functioning is much lower and could be ignored.

\section{B. System with Fault}

Due to a high resistance of superconductors, the SFC that consisting of superconductor material can be destroy easily. As a result of which a large amount of heat is generated during the failure. To protect the superconductor material the stainless-steel thermal coating is done, this took the heat aside from the material. The Switching of superconducting state whether it is zero, normal or high, only relies on the heating of material used in superconductor. If there is any severe fault current flowing, the material used in the superconductor also heats up drastically. With the increase in the heating of the material due to the rise of temp. above threshold, the superconductor also went to operate at high state of resistance. Because of the heating of the superconductor component, the material moves quickly to a standard or high resistance condition. Compared to rapid heating of materials, slow heating of materials increases the transition time. If a significant quantity of fault current is flowing via superconductor during a fault, hot spots can be formed, and thus heating the superconductor element damages the superconductor.

\section{RESULTS AND DISCUSSIONS}

With the implementation of SFCL, the fault current is limited within the first cycle as compared to other system. Simulation results show the effectiveness of the proposed scheme and the ability of SFCL to reduce inrush current. Using SFCL to limit fault current improves system reliability and integrity. The following results have been obtained in the following fault condition with and without SFCL.

\section{A. During LG fault-}

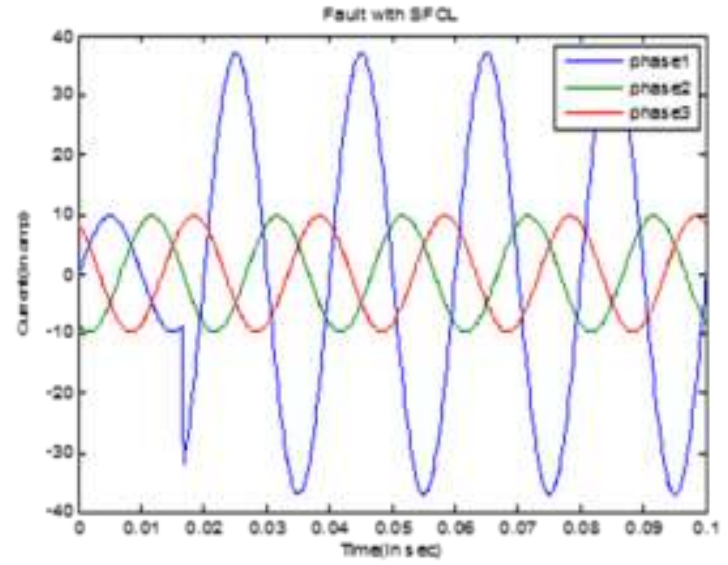

Fig.2(a) shows the current during single phase fault without SFCL.

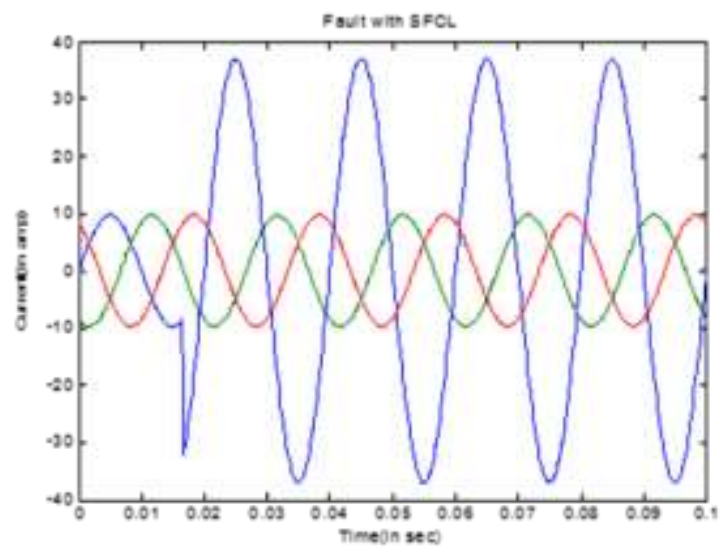

Fig.2(b) shows the current during single phase fault with SFCL.

Fig. 2(a) shows the waveform of single-phase fault without employment of SFCL. It is clear from the figure that in the absence of SFCL, when the fault occurs in one of the phases from three phase system, their occurs high spike om the waveform. Similarly, in case of figure 2 (b) after application of SFCL during occurrence of LG fault, the waveform of current can be seen.

\section{B. During LL Fault}

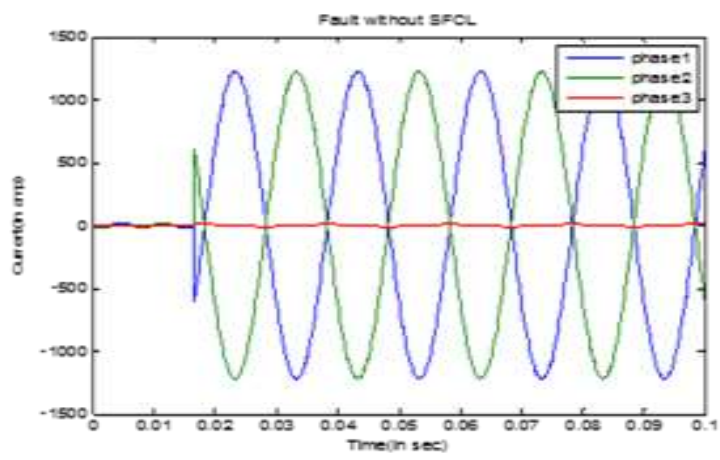

Fig.2(c) shows the current during line to line fault without SFCL. 


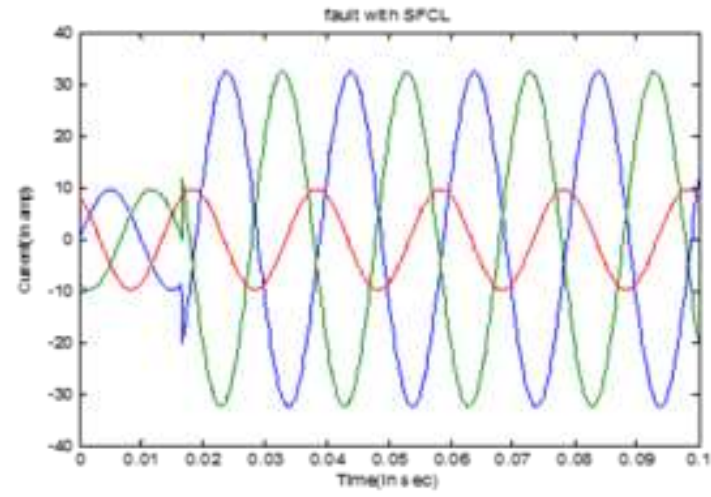

Fig.2(d) shows the current during line to line fault with SFCL.

Fig.2(c) depicted the waveform of current without SFCL at the time of LL fault condition and fig.2(d) illustrate the waveform of current with the SFCL at the time of occurrence of unsymmetrical LL fault.

It is seen that by using SFCL the fault current decreases to $33 \mathrm{amp}$. It's act from the 1st cycle of fault current. In this way SFCL decrease the fault current in single phase fault.

Table:2 - Fault current values for different type fault

\begin{tabular}{|l|l|l|}
\hline \multirow{2}{*}{ TYPE OF FAUIT } & \multicolumn{2}{|c|}{ Magnitude of fanlt curreat(A) } \\
\cline { 2 - 3 } & Without SFCL & With SFCL \\
\hline LQ Fault & 1468 & 38 \\
\hline LL Fault & 1268 & 33 \\
\hline
\end{tabular}

\section{CONCLUSION}

In this proposed paper the implementation of a "superconducting fault current limiter" (SFCL) in a threephase power system for the purpose of fault analysis with unbalanced faults of a single line-to-ground fault and lineto-line fault is performed. From the result it is seen that the value of current is reduced to nearly six times by employing superconducting current limiter within the power system. Therefore, it can be concluded that at the time of fault occurrence within the vast system, the SFCL must be placed to maintain the power flow of the system.

\section{REFERENCES}

1. Devi, A. Rama, and J. Nani Kumar. "Simulation of Resistive Super Conducting Fault Current Limiter and Its Performance Analysis in Three Phase Systems." International Journal of Engineering Research and Technology. Vol. 2. No. 11 (November-2013). ESRSA Publications, 2013.

2. S. Bennett, Insecurity in the supply of electrical energy: an emerging threat? Electr. J. 24 (December (10)) (2011) 51-69.

3. Pushpendra Singh, D. P. Kothari, and Mool Singh "Feasibility of Interconnected Distribution Network for the Integration of Distributed Energy Resources Using GA Approach", International Review of Electrical Engineering, 2013.

4. A. Girgis, and S. Brahma "Effect of Distributed Generation on Protective Device Coordination in Distribution System". Large Engineering Systems Conference on Power Engineering 115-119, 2001.

5. B. W. Lee, J. Sim, K. B. Park, and I. S. Oh "Practical Application Issues of Superconducting Fault Current
Limiters for Electric Power Systems" IEEE Transactions on applied superconductivity, vol. 18, no. 2, june 2008.

6. M. Chen, W. Paul, M. Lakner, L. Donzel, M. Hoidis, P. Unternaehrer, R.Weder, and M. Medik, "6.4 MVA resistive fault current limiter based on $\mathrm{Bi}-2212$ superconductor," Physica C, vol. 372-376, pp. 16571663,2002. [28]M. Lewandowska, R. Wesche, Parametric study for the cooling of high temperature superconductor (HTS) current leads, Cryogenics 53 (January) (2013) 31-36.

7. Llambes, J., C. Weber, and D. Hazelton. "Testing and demonstration results for the transmission-level $(138 \mathrm{kV})$ 2G superconducting fault current limiter at SuperPower." Applied Superconducting Conf., Chicago, Illinois, USA. 2008.

8. Roy, F., Dutoit, B., Grilli, F., Sirois, F., "Magnetothermal finite element modeling of 2nd generation HTS for FCL design purposes.” J. Phys. Conf. Ser. 97, 012286 (2008). 8th European Conference on Applied Superconductivity (EUCAS 2007). 